\title{
A Hybrid Computational Tool to Analyze the Performance of Electric Machines with Reduced Content of Permanent Magnet
}

\author{
R. M. Ram Kumar ${ }^{\dagger}$, Muhammad Raza Khowja ${ }^{\dagger}$, Gaurang Vakil ${ }^{\dagger \ddagger}$, David Gerada ${ }^{\dagger \ddagger}$ \\ Chris Gerada $^{\dagger \ddagger}$, Krzysztof Paciura ${ }^{\S}$, and B. G. Fernandes $₫$ \\ $\dagger$ Power Electronics, Machines and Control Group, University of Nottingham, Nottingham NG7 2RD, U.K, \\ $\ddagger$ Ningbo 315000, China, $\S$ Cummins Corporate R\&T, Peterborough, PE2 6FZ, U.K, \\ I Department of Electrical Engineering, Indian Institute of Technology - Bombay, Powai, Mumbai - 400076, India \\ Email: ramkumar.ramanathan@nottingham.ac.uk, Raza.Khowja@nottingham.ac.uk, gaurang.vakil@nottingham.ac.uk
}

\begin{abstract}
Electric vehicles (EVs) are equipped with interior permanent magnet (IPM) or permanent magnet assisted synchronous reluctance (PM-SynRel) machines because of their superior performance in field weakening region. The effect of saturation is more pronounced in these machines. This prohibits the use of simple analytical tools utilizing constant machine parameters for $d$ and $q$ axis inductance $\left(L_{d}\right.$ and $\left.L_{q}\right)$ from accurately predicting control variables like current advance angle, terminal voltage, torque, etc. As a result, design and optimization of IPM and PM-SynRel machines are constrained to time consuming transient finite element analysis (FEA) performed at rated operating point. A hybrid method is introduced in this paper to estimate the complete torque speed characteristics of IPM and PM-SynRel machines. The hybrid method works by employing simple analytical formulation alongside static FEA, thereby, reducing the computational time by more than 10 times. This enables optimization of electric machines considering complete torque speed characteristics with reduced computational burden. In addition, the accuracy of hybrid method utilizing static FEA is found to be on par with complete transient FEA analysis.
\end{abstract}

Index Terms-IPM, PM-SynRel, reduced PM and Static FEA

\section{INTRODUCTION}

IC engine based conventional drivelines are substituted with electric machines to meet pollution norms set by various governing agencies. These electric machines should inherit high torque density with reduced content of rare earth PM [1]. Reduction in the volume of rare earth PM is necessitated to prevent automotive manufactures from the volatility in its price [2]. Additionally, this has resulted in an extensive search for electric machine topologies with increased torque per magnet volume. Electric machine used in most of the current EVs have IPM with V or triangular structures [3]. This is due to the superior field weakening capability of IPM machines. However, PM-SynRel machines is also known to demonstrates wide field weakening capability and employ reduced volume of PM. PM-SynRel machine with rare earth PM is incorporated in BMW i3 and i8 [4]. Therefore, the future trend is towards increasing the fraction of reluctance torque or reducing the PM mass in electric machines. Consequently, it becomes essential to develop simplistic methods beforehand for the design and analysis of IPM and PM-SynRel with reduced quantity of rare earth PMs.

Permanent magnet synchronous machine (PMSM) is found to deliver poor constant power range despite its superior torque density [5]. The reluctance offered to stator flux is much less in an IPM and PM-SynRel machine compared to a PMSM. This ensures wide field weakening operation without the need for excess inverter capability in an IPM and PM-SynRel machine. However, the effects of saturation becomes more pronounced in these machines [2]. This results in a considerable variation of $\mathrm{d}$ axis inductance $\left(\mathrm{L}_{\mathrm{d}}\right)$ and $\mathrm{q}$ axis inductance $\left(\mathrm{L}_{\mathrm{q}}\right)$. Reluctance component of output torque is altered due to the change in values of $\mathrm{L}_{\mathrm{d}}$ and $\mathrm{L}_{\mathrm{q}}$. Therefore, accommodating this variation is crucial during the performance estimation of both IPM and PM-SynRel machines.

The effect of saturation is significant in the field weakening region of IPM machines [6]. Analytical approximations like fixed permeability method is tested to study the saturation characteristics of PM-SynRel machines [7]. Hybrid method comprising both analytical and 2-D FEA is used to account for skew and cross coupling in [8]. Lumped parameter models to analyze IPM machines for traction application is proposed in [9]. However, none of the available literature provides a tool to segregate IPM machines which are influenced heavily by saturation. Parameter estimation is performed either at constant speed or locked rotor operation [6]. Therefore, inductance variation can be estimated using both static and transient FEA analysis. Computation time required for static FEA analysis is much less compared to transient analysis. In contrast, static analysis does not account for the variation in permeance due to stator slotting.

This paper is organized as follows. The modelling of IPM machines is discussed in Section II. The parameter to segregate machines with extensive influence of magnetic saturation is identified in Section III. This is followed by comparing the estimation of $\mathrm{L}_{\mathrm{d}}$ and $\mathrm{L}_{\mathrm{q}}$ obtained with static and transient FEA analysis for both IPM and PM-SynRel machines in Section IV. Finally, Section V highlights the significance of hybrid 


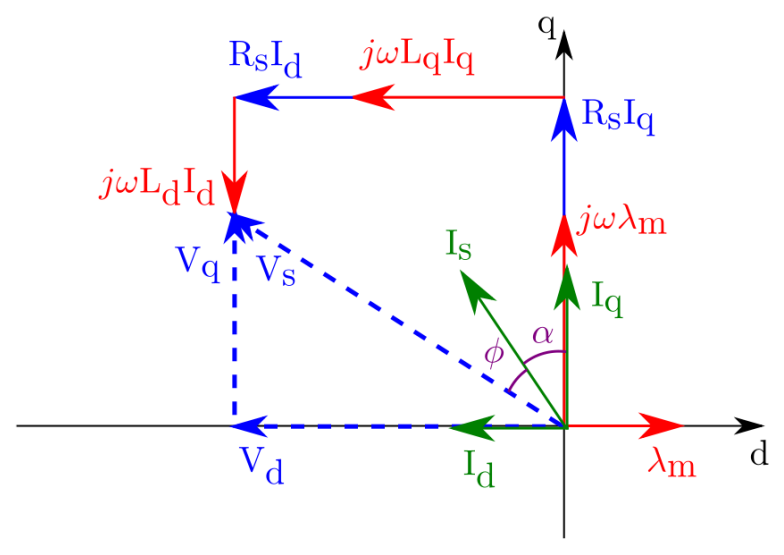

Fig. 1. Phasor diagram for IPM machines

computational tool utilizing static FEA over the conventional methods of analyzing IPM machine.

\section{MOdELLING OF IPM MACHINES}

Electric machines are generally designed for the rated operating conditions [10]. However, wide field weakening is the major requirement for machines used in EVs. Therefore, analysing the entire torque speed characteristics is crucial to understand the performance. The prediction of torque speed characteristics using commercial software packages is cumbersome and time consuming. Consequently, the mathematical formulation required to estimate the entire torque speed characteristics of electric machines will be discussed in this section.

The phasor diagram in terms of dq components is shown in Fig. 1. The stator of the electric machine has three phase distributed winding. Electromagnetic components of the three phase winding like voltage, current, flux linkage and inductance are used in terms of their dq counterpart for the mathematical formulation [11]. This simplifies control and understanding of the electric machines. $d$ component of the voltage $\left(\mathrm{V}_{\mathrm{d}}\right)$ is given in (1) while (2) provides the q component $\left(\mathrm{V}_{\mathrm{q}}\right)$. Here, $\mathrm{R}_{\mathrm{s}}, \mathrm{I}_{\mathrm{d}}, \mathrm{I}_{\mathrm{q}}, \mathrm{L}_{\mathrm{d}}, \mathrm{L}_{\mathrm{q}}, \lambda_{\mathrm{m}}$ and $\omega$ refers to per phase resistance of stator winding, d-axis current, q-axis current, $\mathrm{d}$-axis inductance, q-axis inductance, PM flux linkage and electrical speed respectively.

$$
\begin{gathered}
\mathrm{V}_{\mathrm{d}}=\mathrm{R}_{\mathrm{s}} \mathrm{I}_{\mathrm{d}}+\mathrm{L}_{\mathrm{d}} \frac{\mathrm{dI}}{\mathrm{dt}}-\omega \mathrm{L}_{\mathrm{q}} \mathrm{I}_{\mathrm{q}} \\
\mathrm{V}_{\mathrm{q}}=\mathrm{R}_{\mathrm{s}} \mathrm{I}_{\mathrm{q}}+\mathrm{L}_{\mathrm{q}} \frac{\mathrm{dI}_{\mathrm{q}}}{\mathrm{dt}}+\omega \mathrm{L}_{\mathrm{d}} \mathrm{I}_{\mathrm{d}}+\omega \lambda_{\mathrm{m}}
\end{gathered}
$$

As previously mentioned, obtaining the steady state torque speed envelope is the primary goal. This requires the evaluation of winding parameters in terms of its steady state variables. The $\mathrm{dq}$ components of voltage and current are related to steady state phasor of voltage $\left(\mathrm{V}_{\mathrm{s}}\right)$ and current $\left(\mathrm{I}_{\mathrm{S}}\right)$ by (3) and (4) respectively. The mechanical shaft torque $\left(\mathrm{T}_{\mathrm{em}}\right)$ and power $\left(\mathrm{P}_{\text {out }}\right)$ are given by (5) and (6), respectively.

$$
\begin{gathered}
\mathrm{V}_{\mathrm{s}}=\sqrt{\mathrm{V}_{\mathrm{d}}^{2}+\mathrm{V}_{\mathrm{q}}^{2}} \\
\mathrm{I}_{\mathrm{s}}=\sqrt{\mathrm{I}_{\mathrm{d}}^{2}+\mathrm{I}_{\mathrm{q}}^{2}} \\
\mathrm{~T}_{\mathrm{em}}=3 \frac{\mathrm{P}}{2}\left\{\lambda_{\mathrm{m}} \mathrm{I}_{\mathrm{q}}+\left\{\mathrm{L}_{\mathrm{d}}-\mathrm{L}_{\mathrm{q}}\right\} \mathrm{I}_{\mathrm{d}} \mathrm{I}_{\mathrm{q}}\right\} \\
\mathrm{P}_{\text {out }}=\mathrm{T}_{\mathrm{em}} \omega_{\mathrm{rad}}
\end{gathered}
$$

The output torque and terminal voltage are influenced by the value of current components along the $\mathrm{d}$ and $\mathrm{q}$ axis. Appropriate selection of $I_{d}$ and $I_{q}$ is necessary to extract the maximum possible torque and limit the terminal voltage in the field weakening region. The estimation of $I_{d}$ and $I_{q}$ is also very essential for controlling the machine. $I_{d}$ and $I_{q}$ are related to the stator current as given by (7) and (8) respectively. Conventionally, look up tables are employed due to the heavy saturation present in these machine. Degradation of machine properties with ageing mechanism [12] and continuous change in ambient temperature for EVs demands the estimation of electromagnetic characteristics in real time.

$$
\begin{gathered}
\mathrm{I}_{\mathrm{d}}=-\mathrm{I}_{\mathrm{s}} \cos \alpha \\
\mathrm{I}_{\mathrm{d}}=\mathrm{I}_{\mathrm{s}} \sin \alpha
\end{gathered}
$$

$I_{q}$ is obtained in terms of $I_{s}$ and $I_{d}$ as shown in (9) after rearranging (4). Using binomial expansion, (9) is expanded to obtain the relationship between current component as given by (10) [13]. Steady state terminal voltage is obtained from (3) after eliminating the transient terms present in (1) and (2). Substituting the value of $I_{q}$ from (10) into the steady state voltage equation results in (11). Finally, a cubic equation in terms of $I_{d}$ is obtained. Due to low DC link voltage in EVs, the stator current is high unlike conventional electric machines. This results in a high resistance drop irrespective of the low resistance offered by the stator windings. Therefore, (11) is derived by considering the stator resistance.

$$
\begin{gathered}
\mathrm{I}_{\mathrm{q}}=\sqrt{\mathrm{I}_{\mathrm{s}}^{2}-\mathrm{I}_{\mathrm{d}}^{2}}=\left(\mathrm{I}_{\mathrm{s}}^{2}-\mathrm{I}_{\mathrm{d}}^{2}\right)^{1 / 2} \\
\left(\mathrm{I}_{\mathrm{s}}^{2}-\mathrm{I}_{\mathrm{d}}^{2}\right)^{1 / 2} \approx \mathrm{I}_{\mathrm{s}}-\frac{1}{2} \mathrm{I}_{\mathrm{s}}^{-1} \mathrm{I}_{\mathrm{d}}^{2}=\mathrm{I}_{\mathrm{q}} \\
\left(-\frac{\mathrm{X}_{\mathrm{d}} \mathrm{R}_{\mathrm{s}}}{\mathrm{I}_{\mathrm{s}}}-\frac{\mathrm{X}_{\mathrm{q}} \mathrm{R}_{\mathrm{s}}}{\mathrm{I}_{\mathrm{s}}}\right) \mathrm{I}_{\mathrm{d}}^{3}+\left(-\frac{\mathrm{ER}_{\mathrm{s}}}{\mathrm{I}_{\mathrm{s}}}+\mathrm{X}_{\mathrm{d}}^{2}-\mathrm{X}_{\mathrm{q}}^{2}\right) \mathrm{I}_{\mathrm{d}}^{2} \\
+\left(-2 \mathrm{EX}_{\mathrm{d}}+2 \mathrm{X}_{\mathrm{d}} \mathrm{I}_{\mathrm{s}} \mathrm{R}_{\mathrm{s}}+2 \mathrm{X}_{\mathrm{q}} \mathrm{I}_{\mathrm{s}} \mathrm{R}_{\mathrm{s}}\right) \mathrm{I}_{\mathrm{d}} \\
+\left(\mathrm{E}^{2}-\mathrm{V}_{\mathrm{s}}^{2}+2 \mathrm{ER}_{\mathrm{s}} \mathrm{I}_{\mathrm{s}}+\mathrm{R}_{\mathrm{s}}^{2} \mathrm{I}_{\mathrm{s}}^{2}+\mathrm{X}_{\mathrm{q}}^{2} \mathrm{I}_{\mathrm{s}}^{2}\right)=0
\end{gathered}
$$

Above mentioned derivation is based on the assumption that the maximum available stator current is constant. This is extensively valid for EVs where the maximum input current available from the converter is curtailed to a predefined value. 


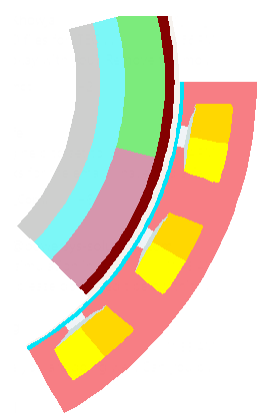

(a)

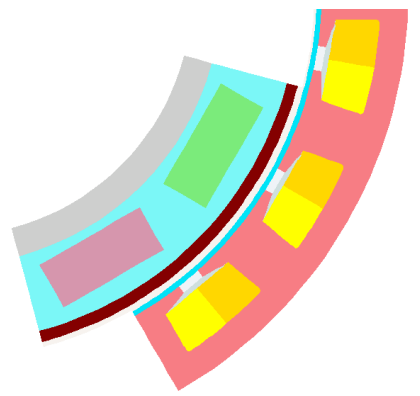

(b)

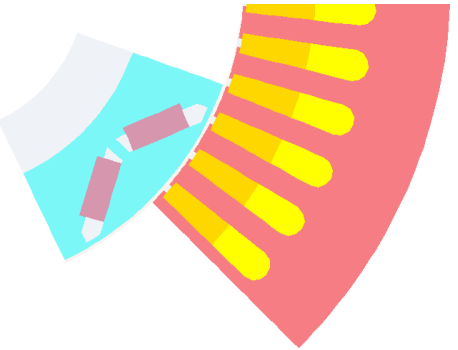

(c)

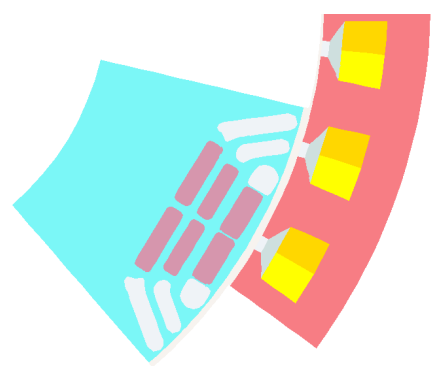

(d)

Fig. 2. Structure of rotor in (a) PMSM (Machine 1) (b) IPM with high PM torque (Machine 2) (c) IPM with high reluctance torque (Machine 3) and (d) PM-SynRel (Machine 4)

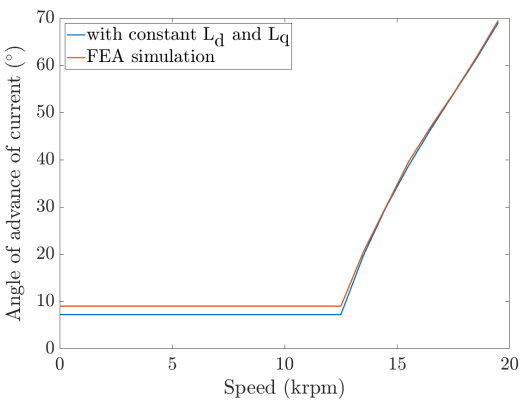

(a)

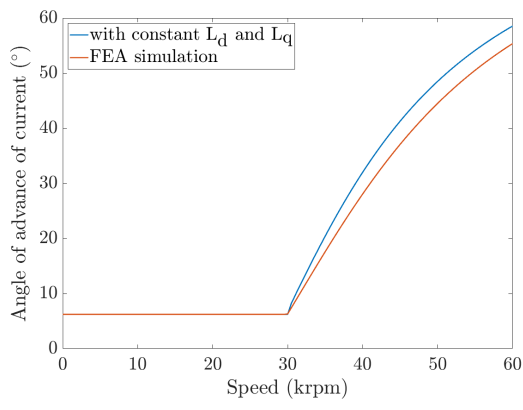

(b)

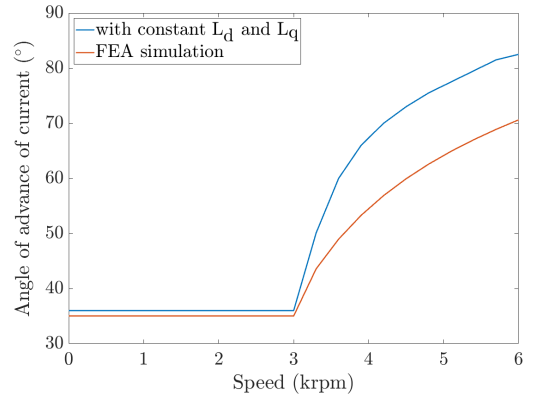

(c)

Fig. 3. Current advance angle in (a) PMSM (b) IPM with high PM torque (c) IPM with high reluctance torque

TABLE I

OUTPUT FROM ALL CONFIGURATION

\begin{tabular}{cccccc}
\hline \hline Parameters & Machine 1 & Machine 2 & Machine 3 & Machine 4 & Unit \\
\hline Machine Type & $\begin{array}{c}\text { Halbach surface } \\
\text { mount PMSM } \\
\text { Concentrated }\end{array}$ & $\begin{array}{c}\text { IPM with interior } \\
\text { flat PM } \\
\text { Concentrated }\end{array}$ & $\begin{array}{c}\text { IPM with V } \\
\text { shaped barrier } \\
\text { Distributed }\end{array}$ & $\begin{array}{c}\text { PM-SynRel } \\
\text { machine } \\
\text { Distributed }\end{array}$ & - \\
Winding Configuration & 1080 & 500 & 600 & 470 & $\mathrm{~V}$ \\
DC-Link Voltage & 0.944 & 0.95 & 0.95 & 0.95 & - \\
Modulation Index & 14 & 30 & 3 & 2.8 & $\mathrm{krpm}$ \\
Rated speed & 25 & 60 & 6 & 15 & $\mathrm{krpm}$ \\
Maximum speed & 0.34 & 0.32 & 0.878 & 0.47 & $\mathrm{mH}$ \\
d-axis inductance & 0.35 & 0.36 & 1.686 & 0.96 & $\mathrm{mH}$ \\
q-axis inductance & 60 & 12 & 96 & 170 & $\mathrm{mV} . \mathrm{s}$ \\
No-load flux linkage & 60 \\
\hline \hline
\end{tabular}

The hybrid method works by first calculating $I_{d}$ using (11). All the other values required for solving (11) are computed beforehand. $X_{d}$ and $X_{q}$ are highly nonlinear and depend on the operating point of the machine in the torque speed plane. Therefore, these values are computed using static or transient FEA. The significance of static over transient FEA will be highlighted in the subsequent sections. After $I_{d}$ is obtained, (7) is used to calculate the value of current advance angle.

\section{IMPACT OF INCREASED RELUCTANCE TORQUE}

Electric machines with significant fraction of reluctance torque are necessary to reduce PM content. This is enabled by using IPM and PM-SynRel machines. Optimization is the most time consuming and significant phase of electric machine design. Currently, reduction in volume of PM is one of the main constraint imposed during optimization. In addition, wide constant power operation is desired from electric machines installed in EVs. This necessitates all feasible designs of IPM and PM-SynRel machines to satisfy the entire torque speed characteristics. However, heavy computation cost involved in transient FEA analysis makes it undesirable to be used for estimating the complete torque speed characteristics. Consequently, it becomes essential to use simple analytical formulations as described in the previous section. The applicability of these mathematical models on machines with low PM content and need for modifications is presented in this section.

Three different electric machines, namely, machine 1,2 and 3 as shown in Figs. 2(a), 2(b) and 2(c) with parameters listed in Table I and varied PM content are analyzed to understand the significance of saturation. IPM machines with V shaped flux barrier and interior flat magnets are selected to represent electric machine with high reluctance torque and high PM torque, respectively. The current advance angle calculated from analytical and mathematical models using fixed machine 


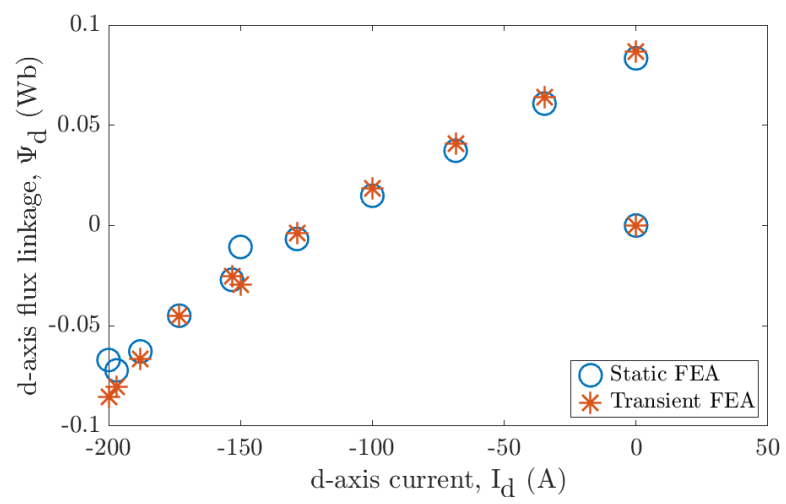

(a)

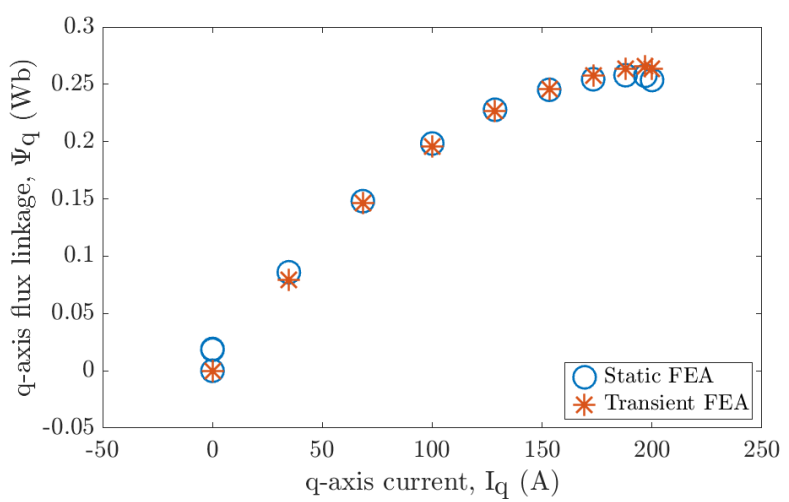

(b)

Fig. 4. Comparison between static and transient FEA for machine 3 based on flux linkage along (a) d-axis and (b) q-axis

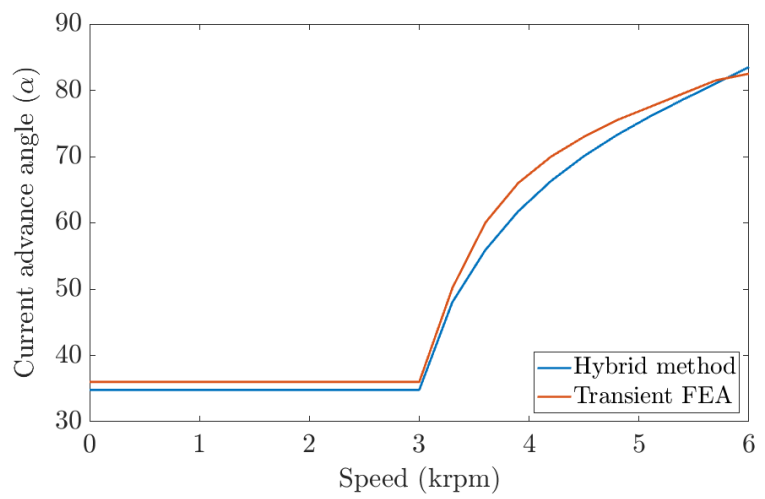

(a)

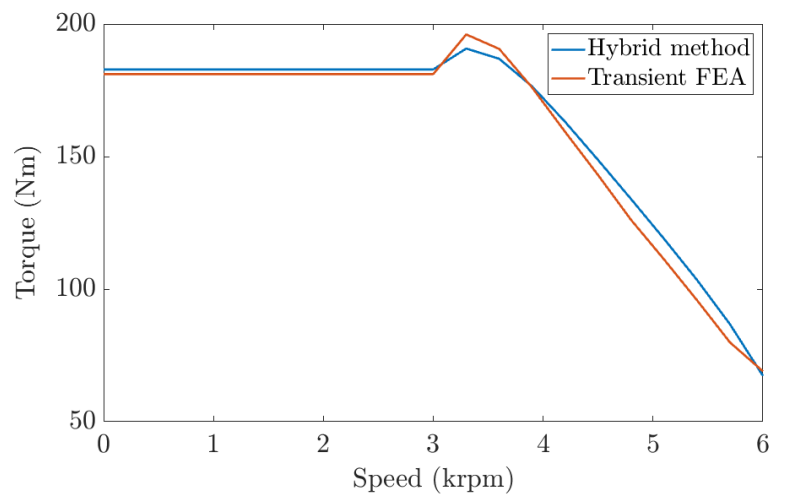

(b)

Fig. 5. Comparison between hybrid method and transient FEA for machine 3 using (a) current advance angle and (b) complete torque-speed characteristics

parameters for a PMSM, IPM with high PM content and IPM with low PM content are shown in Figs. 3(a), 3(b) and 3(c) respectively. The fraction of PM torque is $1,0.7$ and 0.4 in these machines. The value of current advance angle calculated using analytical formulation is found to deviate significantly from FEA results with the reduction in volume of PM. The error between FEA and analytical calculation is less than \pm $5 \%$ for machines 1 and 2 . This is due to the high PM content in these machine compared to machine 3.

The current advance angle calculated with constant $\mathrm{L}_{\mathrm{d}}$ and $\mathrm{L}_{\mathrm{q}}$ for an IPM with more reluctance torque or machine 3 is considerably away from the actual value as shown in 3(c). The demagnetizing stator flux at rated speed is much less compared to the maximum speed of operation. Therefore, saturation of rotor is high at the rated speed. This results in reduced values for $\mathrm{L}_{\mathrm{d}}$ and $\mathrm{L}_{\mathrm{q}}$ at rated speed. Based on this, analytical method employing constant inductance is found to use a lesser value for $\mathrm{L}_{\mathrm{d}}$ and $\mathrm{L}_{\mathrm{q}}$ in the field weakening region. Hence, the results obtained with both methods are found to be very different.

A ratio between no load induced voltage and rated terminal voltage is identified to be used as an indicator for segregating IPM and PM-SynRel machines having high influence of rotor saturation. Based on this, electrical machines with values greater that 0.65 are analyzed with constant machine parameters. In contrast, partial FEA modelling utilizing static or transient FEA in conjunction with simple analytical formulation is necessary to account for the variation of $\mathrm{L}_{\mathrm{d}}$ and $\mathrm{L}_{\mathrm{q}}$ in electric machines with the ratio less than 0.65 .

\section{COMPARISON BETWEEN HYBRID METHOD AND TRANSIENT FEA}

The hybrid method works by utilizing static FEA alongside simple analytical formulation presented in Section II. As previously mentioned, the values of $\mathrm{L}_{\mathrm{d}}$ and $\mathrm{L}_{\mathrm{q}}$ vary significantly in the field weakening region. $\mathrm{L}_{\mathrm{d}}$ and $\mathrm{L}_{\mathrm{q}}$ are estimated from their respective flux linkage using (12) and (13). Static FEA is used to calculate the flux linking in stator winding. This is then converted to their dq counterparts by Park's transformation. The application of hybrid method for estimating the performance of IPM and PM-SynRel machines is discussed in this section.

$$
\begin{gathered}
\mathrm{L}_{\mathrm{d}}=\frac{\lambda_{\mathrm{d}}}{\mathrm{I}_{\mathrm{d}}} \\
\mathrm{L}_{\mathrm{q}}=\frac{\lambda_{\mathrm{q}}-\lambda_{\mathrm{m}}}{\mathrm{I}_{\mathrm{q}}}
\end{gathered}
$$

\section{A. IPM machine}

$\mathrm{d}$ and $\mathrm{q}$ axis flux linkage obtained using static and transient FEA analysis for machine 3 are compared in Figs. 4(a) and 


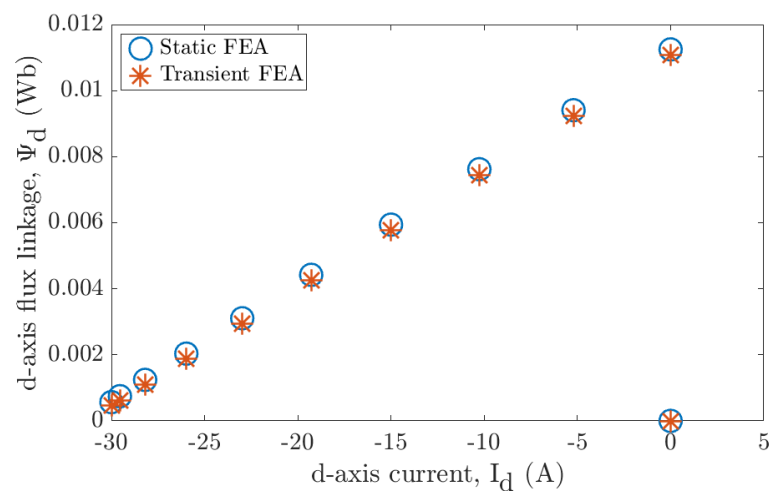

(a)

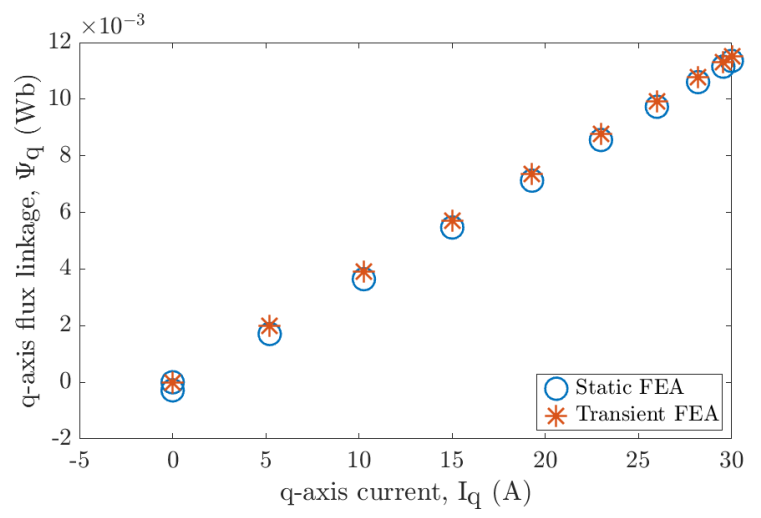

(b)

Fig. 6. Comparison between static and transient FEA for machine 2 based on flux linkage along (a) d axis and (b) q axis

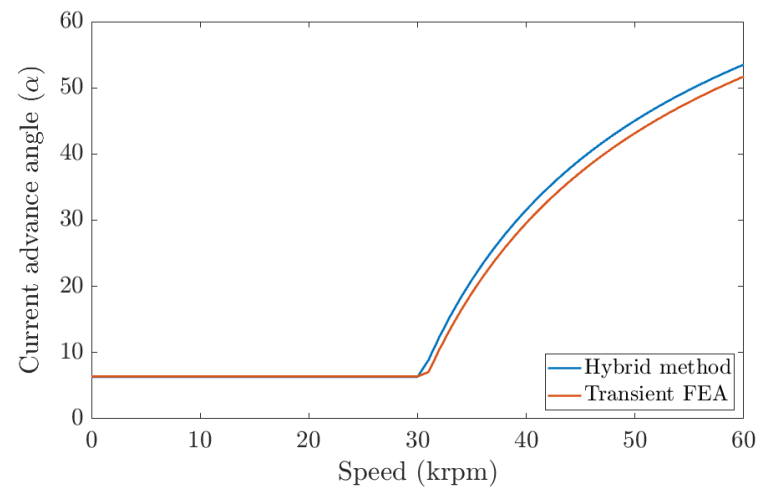

(a)

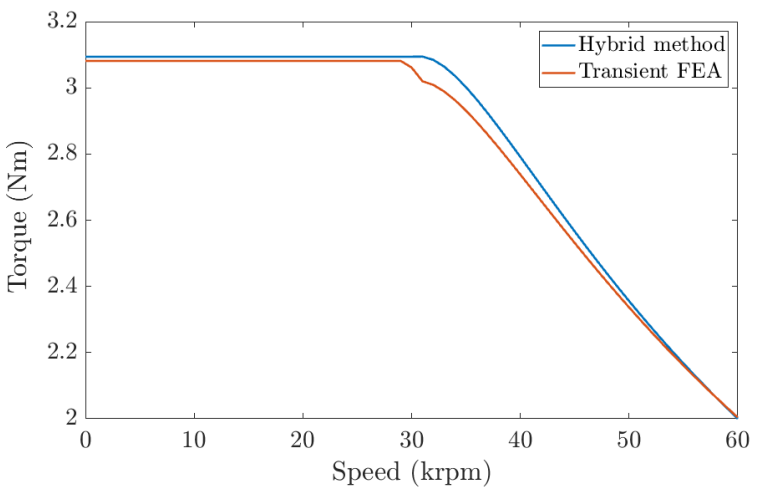

(b)

Fig. 7. Comparison between hybrid method and transient FEA for machine 2 using (a) current advance angle and (b) complete torque-speed characteristics

4(b). The results from static and transient FEA are found to match very closely. Therefore, flux linkage calculated from static FEA is sufficient to determine the variation in $\mathrm{L}_{\mathrm{d}}$ and $\mathrm{L}_{\mathrm{q}}$ using (12) and (13) respectively. The value of current advance angle calculated after incorporating the results of static FEA is shown in Fig. 5(a). Hybrid method is found the calculate current advance angle with higher accuracy as shown in Fig. 5(a) compared to pure analytical formulation given in Fig. 3(c). The torque speed characteristics computed using hybrid method is shown in Fig. 5(b). The error between transient FEA and hybrid calculation is less than $\pm 5 \%$ in an IPM machine with low PM content. In addition, computation time is reduced by more that 10 times using the hybrid model. This proves the superiority of hybrid model over complete analytical formulation with constant machine parameters and transient FEA for an IPM machine with low PM content.

Hybrid method is also implemented on machine 2 for completeness. The flux linkage obtained using static and transient FEA along $\mathrm{d}$ and $\mathrm{q}$ axis are found to match very closely as shown in Figs. 6(a) and 6(b). The comparison of current advance angle and torque for IPM with high PM torque are shown in Figs. 7(a) and 7(b) respectively. The error between transient FEA and hybrid calculation is found to be less than $\pm 5 \%$ even in case of machine 2 with high PM torque.

\section{B. PM-SynRel machine}

PM-SynRel machines are the ideal choice to reduce volume of PM and realize wide field weakening operation as desired in EVs. The hybrid method is implemented on a PM-SynRel machine as shown in Fig. 2(d) with rated and maximum speed of 2800 and $15000 \mathrm{rpm}$ respectively. The parameters of the PM-SynRel are given under machine 4 in Table I. The current advance angle and torque speed characteristics computed using the hybrid method with static FEA are compared to the transient FEA analysis in Figs. 8(a) and 8(b) respectively. Unlike the IPM machines, current advance angle and torque are computed at different values of current to encompass the entire torque speed plane for the PM-SynRel machine.

An admirable match is observed between the results of hybrid method and transient FEA as shown in Figs. 8(a) and 8(b) for the entire torque speed plane. However, quantification of these results is essential to understand the impact of variation in stator current on the hybrid formulation. The error between hybrid method and transient FEA is calculated and plotted in Fig. 9. The average error between hybrid method and transient FEA is found to be less than $10 \mathrm{Nm}$ for all values of stator current. In addition, the range over which error in torque varies is found to decrease with the value of stator current. Therefore, it is possible to estimate the electromagnetic performance in all types of electric machine including machines with low PM 


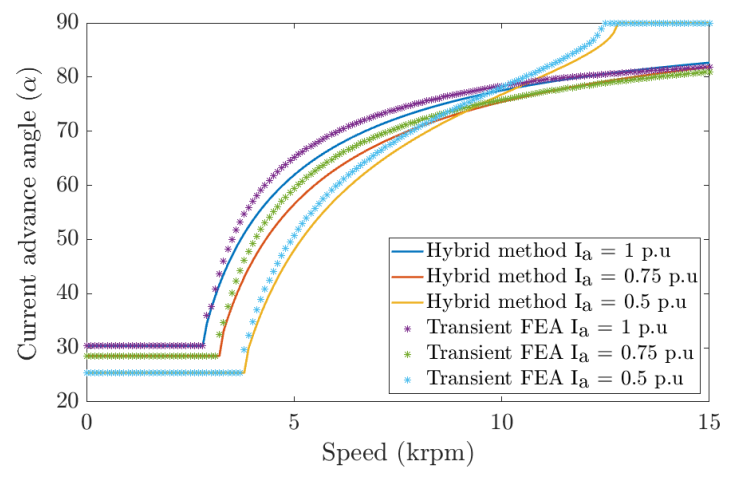

(a)

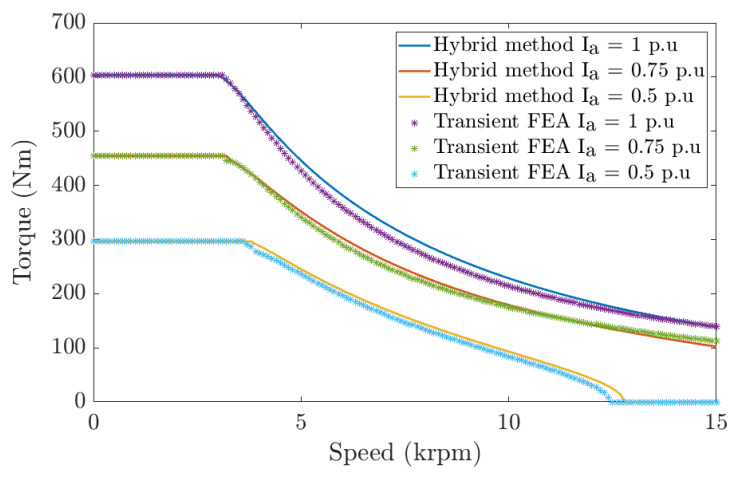

(b)

Fig. 8. Comparison between hybrid method and transient FEA for PM-SynRel machine using (a) current advance angle (b) complete torque-speed characteristics

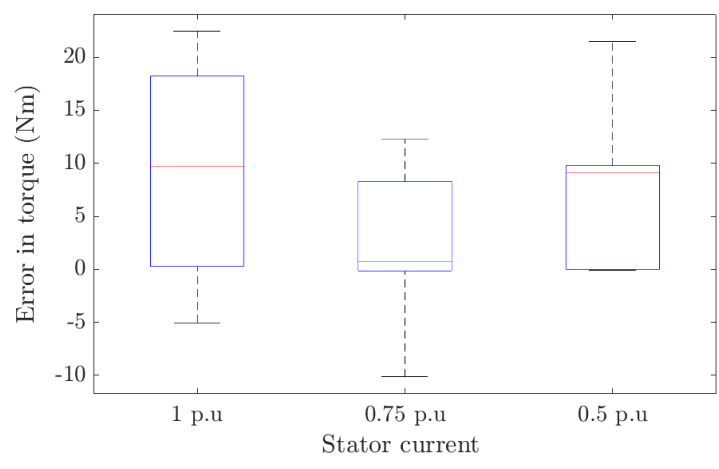

Fig. 9. Error in torque for PM-SynRel machine

torque using the computationally efficient hybrid method.

\section{CONCLUSION}

IPM and PM-SynRel machines with reduced content of PM are employed in EVs. The effect of rotor saturation is significant in the field weakening region of these machines. This prohibits simple analytical models from accurately predicting the performance of IPM and PM-SynRel machines. Therefore, a hybrid method utilizing static FEA analysis is cooperation with simple analytical formulation is introduced in this paper. The major outcomes of this are as follows:

- Ratio between no load and rated terminal voltage is identified as a parameter to segregate machines with high influence of rotor saturation like IPM machines with low PM content and PM-SynRel machines.

- The accuracy of hybrid method is on par with time consuming transient FEA.

- Predicting the electromagnetic performance with hybrid method is computationally more efficient and 10 times faster compared to transient FEA.

- It is easier to estimate the entire torque speed characteristics with hybrid method. This extends the scope of optimization which is conventionally based on rated operating conditions.

- Hybrid method is also found to efficiently compute the torque speed characteristics for all value of stator current.

\section{REFERENCES}

[1] Advanced Propulsion Centre. The roadmap report towards 2040: A guide to automotive propulsion technologies. Automotive Council UK.

[2] G. Pellegrino, T. M. Jahns, N. Bianchi, W. L. Soong, and F. Cupertino, The rediscovery of synchronous reluctance and ferrite permanent magnet motors: tutorial course notes. Springer, 2016.

[3] T. A. Burress, S. L. Campbell, C. Coomer, C. W. Ayers, A. A. Wereszczak, J. P. Cunningham, L. D. Marlino, L. E. Seiber, and H.T. Lin, "Evaluation of the 2010 toyota prius hybrid synergy drive system," Oak Ridge National Lab.(ORNL), Oak Ridge, TN (United States). Power ..., Tech. Rep., 2011.

[4] J. Merwerth, "The hybrid-synchronous machine of the new bmw i3 \& i8 challenges with electric traction drives for vehicles. bmw group," in Workshop University Lund: Lund, 2014.

[5] M. Raza Khowja, G. Vakil, C. Gerada, T. Yang, S. Bozhko, and P. Wheeler, "Genetic algorithm based geometrical optimisation of dual three-phase pmsm for an aircraft starter/generator application," in 10th IET International Conference on Power Electronics, Machines and Drives (PEMD 2020),2020, (In Press).

[6] B. Stumberger, G. Stumberger, D. Dolinar, A. Hamler, and M. Trlep, "Evaluation of saturation and cross-magnetization effects in interior permanent-magnet synchronous motor,' IEEE Transactions on Industry Applications, vol. 39, no. 5, pp. 1264-1271, Sep. 2003.

[7] Sang-Yeop Kwak, Jae-Kwang Kim, and Hyun-Kyo Jung, "Characteristic analysis of multilayer-buried magnet synchronous motor using fixed permeability method," IEEE Transactions on Energy Conversion, vol. 20, no. 3, pp. 549-555, Sep. 2005

[8] G. Qi, J. T. Chen, Z. Q. Zhu, D. Howe, L. B. Zhou, and C. L. Gu, "Influence of skew and cross-coupling on flux-weakening performance of permanent-magnet brushless ac machines," IEEE Transactions on Magnetics, vol. 45, no. 5, pp. 2110-2117, May 2009.

[9] K. D. Hoang and K. Atallah, "Rapid sizing concept of interior permanent magnet machine for traction applications," The Journal of Engineering, vol. 2019, no. 17, pp. 3956-3961, 2019.

[10] M. R. Khowja, G. Vakil, C. Gerada, T. Yang, S. Bozhko, and P. Wheeler, "Trade-off study of a high power density starter-generator for turboprop aircraft system," in IECON 2019 - 45th Annual Conference of the IEEE Industrial Electronics Society, vol. 1, 2019, pp. 1435-1440.

[11] Y. Chen, S. Bozhko, L. Fan, T. Yang, and M. R. Khowja, "Decoupled model for asymmetrical dual three phase permanent magnet synchronous machine," in 2019 IEEE International Electric Machines Drives Conference (IEMDC), 2019, pp. 1971-1976.

[12] G. Turabee, M. R. Khowja, P. Giangrande, V. Madonna, G. Cosma, G. Vakil, C. Gerada, and M. Galea, "The role of neural networks in predicting the thermal life of electrical machines," IEEE Access, vol. 8, pp. 40 283-40297, 2020.

[13] M. R. Khowja, G. Vakil, and C. Gerada, "Analytical tool to generate torque-speed characteristics for surface mounted pm machines in constant torque and field weakening regions," in IECON 2019 - 45th Annual Conference of the IEEE Industrial Electronics Society, vol. 1, 2019, pp. 922-927. 